\title{
DEATHS ON RAIL ROADS: A STUDY FROM COLOMBO NORTH TEACHING HOSPITAL, SRI LANKA
}

\author{
Paranitharan P. \& Perera W.N.S \\ Department of Forensic Medicine, Faculty of Medicine, University of Kelaniya, Sri Lanka \\ Corresponding author: Paranitharan P.
}

Email: paran28@gmail.com

iD https:/ / orcid.org / 0000-0002-1913-6085

\begin{abstract}
In Sri Lanka railway related deaths are reported throughout the year. Most accidental deaths occur due to negligent behaviour of pedestrians and drivers. Fatal train impacts cause extensive visceral and musculoskeletal injuries due to the nature of the object as well as the amount of force transmitted during impact. A study of this nature would help ascertain demographic details of victims, characteristics of the incident of fatal train crashes and recognize the injury profile. An autopsy based retrospective study was done using postmortem reports of 10 years. Seventy autopsy reports from Colombo North Teaching Hospital between July 2006 and July 2016 were analyzed. Data regarding demographic details of victim and incident, external and internal injury distribution, cause and manner of death as determined at autopsy were extracted. Majority of victims were males between 20-39 years $(43.7 \%, n=32)$ of age and were married $(64.3 \%, n=45)$. Most victims of accidents were trespassers $68.8 \% \quad(n=33)$. $68.6 \%(n=48)$ and $31.4 \%(n=22)$ respectively were due to accidents and suicide. The highest number of fatalities $64.3 \%(n=45)$ were observed between $2 \mathrm{pm}$ to $10 \mathrm{pm}$. The number of external injuries were more in accidents than suicides. The most common cause of death was multiple injuries. Majority of the deaths were accidental. Transections of neck, chest and traumatic amputations of extremities were common in suicides than accidents.
\end{abstract}

Key words: death; railroad; accident; suicide

All articles in Sri Lanka Journal of Forensic Medicine, Science \& Law are licensed under the terms of the Creative Commons Attribution-Non Commercial 4.0 International License. 


\section{INTRODUCTION}

Sri Lanka has a railroad transport system which consist of 1,567.62 kilometers of rail track with 360 railway stations. The Sri Lankan railway system operates 396 trains and transports around 3.72 million passengers daily and more than 92 million passengers annually. ${ }^{1}$ Traffic related deaths and injuries are an identified problem in Sri Lanka. Statistics reveal that approximately 250 people have died in train accidents during the year 2016.

No comprehensive studies have been carried out on railroad accidents in the recent past in Sri Lanka to provide reliable statistics. However, reports of incidents in the national newspapers indicate that most deaths that occur on railway tracks are not due to factors related to the train itself (derailment, mechanical errors of the train or track) but the result of careless use of rail crossings in places without barrier or signaling, attempting suicide or usage of rail track by trespassers. Vehicular-train crashes as well as pedestrian-train crashes are seen at unsafe crossings, creating public turmoil. In some instances, accidents occur at the crossings as well as on the track because of lack of attention to train signals by the level crossers or the "pedestrians" on the rail track.

Based on published information, fatalities are rare among train passengers while travelling or employees of the railway department. $^{2,3}$

Fatal train impacts cause severe injuries on the victims due to the nature of the object as well as the amount of force transmitted during the impact. Extensive visceral and musculoskeletal injuries are evident due to the dynamic nature of the incident and due to run over by wheels. Injuries such as decapitations, transection of the body and amputations are observed mostly in rail road deaths than on regular roads. However, the published literature does not reveal recent studies related to epidemiology and injury profile related to train crashes in Sri Lanka. ${ }^{4}$ It is envisaged that this study will help to recognize the injury pattern and trends in rail road fatalities.

\section{OBJECTIVES}

With regard to deaths on rail roads to determine;

- the socio-demographic profiles of the victims

- characteristics of the incident

- injury profile

\section{METHODOLOGY}

An autopsy based retrospective study was undertaken using postmortem reports of 10 consecutive years. Postmortem reports of deaths following collision with a train, which were referred to the Colombo North Teaching hospital, Ragama, Sri Lanka, for medico legal autopsy, between 2006 July to 2016 July were perused. Cases included those who had fatal injuries following impact with a train while travelling in the train or other vehicle, while using rail track for walking or crossing or attempted suicide on track. Information including demographic details of victim, nature of incident, physical disabilities, reasons for collision with a train, time and month of incident, place of collision, external and internal injury distribution and cause and manner of death as determined by autopsy were extracted, maintaining confidentiality. 


\section{RESULTS}

Seventy reports of rail road fatalities were identified.

\section{Socio-demographic profile}

Seventy nine percent were male.

\section{Table 1: Age of victims}

\begin{tabular}{|c|c|}
\hline Age (yrs.) & Number (\%) \\
\hline$<19$ & $01(1 \%)$ \\
\hline $20-39$ & $32(46 \%)$ \\
\hline $40-59$ & $18(26 \%)$ \\
\hline$>60$ & $18(26 \%)$ \\
\hline Not known & $01(1 \%)$ \\
\hline
\end{tabular}

The average age at death was 43 years. The age of males ranged from 19 to 75 years and females from 21 to 78 years. Majority of victims were males between 20-39 years of age.

\section{Characteristics of the incident}

There were $48(69 \%)$ accidental deaths and $22(31 \%)$ suicidal deaths. Among them six were train-vehicular collisions causing 9 $(13 \%)$ fatalities and $61(87 \%)$ were trainperson collisions. Victims accidental train vehicular collisions includes 3 ( 6\%) motor cycle riders, 2 (4\%) motor cycle occupants, $1(2 \%)$ bicycle rider, 1 (2\%) truck driver, and $2(4 \%)$ occupants of a three wheeler.

All suicides were of pedestrians. Collision occurred on the rail track away from the station in $20(91 \%)$ cases and close to the rail crossing in $2(9 \%)$ cases.

Two commuters (4\%) had fatal injuries; one slipping while getting into a moving train and the other falling on to the rail track while running on the platform to catch a moving train. A single blind person sustained injuries while getting down from the train before it had stopped.

\section{Possible contributory factors relating to victim}

Among the accidental deaths there was a history of consumption of alcohol prior to the incident in 14 (29\%) fatalities, physical disability (blindness, hearing impairment and difficulty in walking) in 4 (8\%) cases, engaging in unsafe practices such as getting into a moving train in $2(4 \%)$ cases and improper use of level crossing by pedestrians, driver and a rider in $5(10 \%)$ cases.

Among the victims of suicide five (23\%) had been diagnosed with psychiatric disease and $6(27 \%)$ had a history of alcohol abuse.

\section{Survival period of victim}

Sixty three (90\%) victims were dead on admission to the Hospital. Seven (10\%) were alive with injuries and were admitted to the primary care unit of the hospital. Five (7\%) died during resuscitation, 2 (3\%) survived, 1-4 days. There were no long term survivals.

\section{Identity of victim}

The identity of a majority (79\%) of victims was established at the time of admission to hospital by a known person or using identification documents such as national identity cards, ATM cards, credits cards or driving licenses. Fifteen (21\%) dead bodies were brought to hospital without proper identification. Necessary action was taken by the police to establish identity of these persons. Eight (11\%) were identified within 48 hours while 6 (9\%) took 2- 4 days. Relatives of a deceased were contacted by using a visiting card of a lawyer which was found in an inner pocket of the deceased during the autopsy which was conducted after 3 months. One body was disposed of after the autopsy without establishing the identity which was not included in the study sample. 
The following figure illustrates the different circumstances of death.

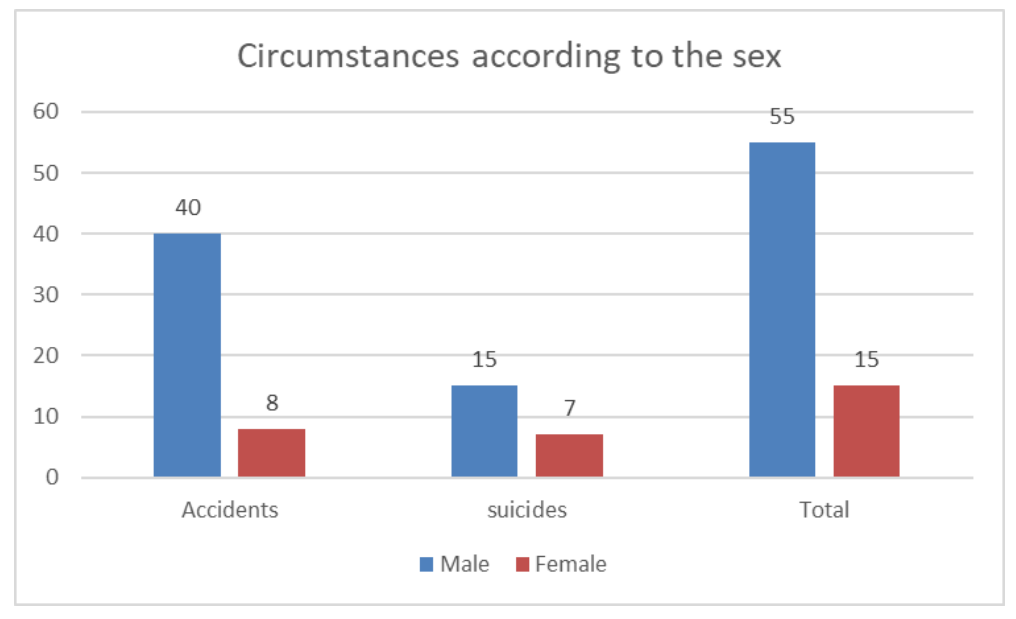

Sixty nine percent $(n=48)$ were accidental while the rest were suicidal. Homicidal deaths or post mortem disposal was not observed. Accident was the foremost apparent manner of death among males $73 \%(n=40)$ (Figure 1).

Figure 1: Circumstances of death

Table 2: Circumstances of death with age

\begin{tabular}{|c|c|c|cc|}
\hline Age (years) & Accidents & Suicides & \multicolumn{2}{|c|}{ Total } \\
\hline $\mathbf{1 9}$ & $01(2 \%)$ & - & 01 & $(1 \%)$ \\
\hline $\mathbf{2 0 - 3 9}$ & $18(38 \%)$ & $14(64 \%)$ & 32 & $(46 \%)$ \\
\hline $\mathbf{4 0 - 5 9}$ & $15(31 \%)$ & $03(14 \%)$ & 18 & $(26 \%)$ \\
\hline$>60$ & $14(29 \%)$ & $04(18 \%)$ & 18 & $(26 \%)$ \\
\hline Not known & - & $01(5 \%)$ & 01 & $(1 \%)$ \\
\hline Total & $\mathbf{4 8}$ & $\mathbf{2 2}$ & $\mathbf{7 0}$ \\
\hline
\end{tabular}

Accidents are distributed between different age groups while suicidal tendencies were mostly apparent in those between ages of 20-39 years (Table2).

Police investigation related to the incident revealed a history of jumping in front of the train, lying down or standing on the rail track as modes of suicidal.

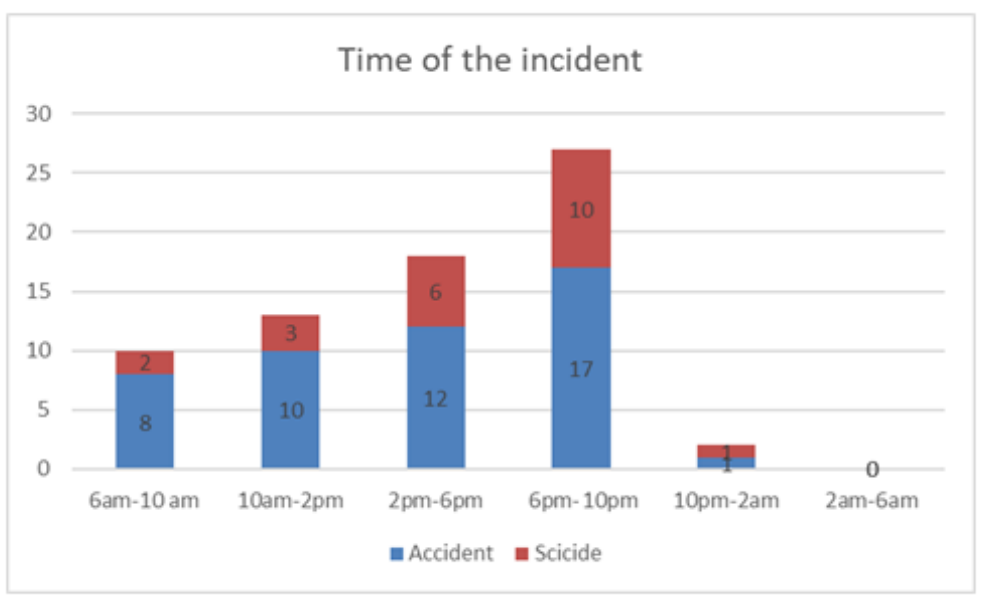

The highest number of fatalities $64 \% \quad(n=45)$ were observed between $2 \mathrm{pm}$ to $10 \mathrm{pm}$. Sixty three percent $(n=30)$ of accidents occurred during day light (6 am to $6 \mathrm{pm}$ ) whilst suicides showed a higher frequency $77 \% \quad(n=17)$ in the evening and night. This was statistically significant (Figure 2).

Figure 2: Time of day vs circumstances 


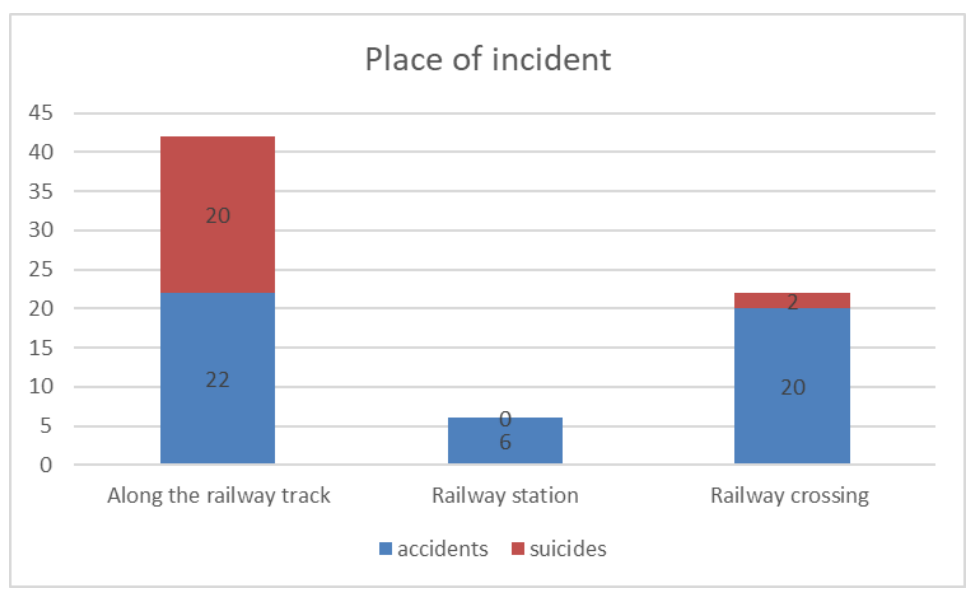

The place of incident included railway station (and surrounding), rail track away from station, protected/ unprotected level crossings or close to the level crossing. (Figure 3) Rail track, railway station or the rail crossings are not safe for the users showing 22 (45.8\%), 6 (12.5\%) and 20 (41.7\%) accidental fatalities respectively in these locations.

Figure 3: Place of incident and circumstance

Histories revealed that victims used the rail track as a short cut to reach their destinations or crossed the path in hurry without proper attention to approaching trains. One person was using a mobile phone with ear phones at the time of impact with train. In two (4\%) cases the rail track was the only path home.

Of the incidents at railway crossings, there were nine fatalities $(19 \%)$ due to the direct impact of a vehicle and 11 (22.9\%) pedestrians fatalities by the train at the level crossing. In $3(6 \%)$ instances the level crossings were unprotected and there were no signal lights. Five (10\%) incidents were due to the unsafe practices of persons, crossing the rail track while the gate was closed or while the signal light was on. In 2 cases $(4 \%)$ the signal lights did not indicate an oncoming train. Another impact was due inadequate visibility of rail road due to trees and a bend. Records were inadequate to identify reasons for crash in other instances.

Most suicide attempts $(n=20)(91 \%)$ were at lonely places of rail track and only $2(9 \%)$ occurred close to the rail crossing. There were no suicide attempts at or near the railway station.

\section{Injury profile}

\section{Types of injuries}

The following indicates the injury distribution following accidents and suicides.

Table 3 : Head and neck injuries

\begin{tabular}{|l|l|l|l|l|l|l|}
\hline \multirow{2}{*}{ Type of Injury } & \multicolumn{5}{|c|}{ Accidents } & \multicolumn{3}{c|}{ Suicides } \\
\cline { 2 - 7 } & Scalp & Face & Neck & Scalp & Face & Neck \\
\hline Abrasion & $6(16 \%)$ & $18(47 \%)$ & $7(64 \%)$ & $6(27 \%)$ & $5(24 \%)$ & $4(33 \%)$ \\
\hline Contusion & $11(29 \%)$ & $2(5 \%)$ & $2(18 \%)$ & $2(10 \%)$ & $2(10 \%)$ & $2(17 \%)$ \\
\hline Laceration & $18(47 \%)$ & $17(45 \%)$ & $2(18 \%)$ & $13(60 \%)$ & $10(48 \%)$ & $3(25 \%)$ \\
\hline Degloving injury & $3(8 \%)$ & & & & & \\
\hline Eye avulsion & & $1(3 \%)$ & & & $2(10 \%)$ & \\
\hline Facial mutilation & & & & & $2(10 \%)$ & \\
\hline Decapitation & & & & & & $3(25 \%)$ \\
\hline Total & $\mathbf{3 8}$ & $\mathbf{3 8}$ & $\mathbf{1 1}$ & $\mathbf{2 1}$ & $\mathbf{2 1}$ & $\mathbf{1 2}$ \\
\hline
\end{tabular}


The occurrence of scalp lacerations were more in suicides (60.2.7\%) than accidents. (47.4\%). Decapitations were observed in $25 \%$ of suicidal cases.

Table 4: External chest injuries

\begin{tabular}{|l|l|l|l|l|}
\hline \multirow{2}{*}{$\begin{array}{c}\text { Type of } \\
\text { Injury }\end{array}$} & \multicolumn{4}{|c|}{ Number of cases } \\
\cline { 2 - 5 } & \multicolumn{2}{|c|}{ Accidents } & \multicolumn{2}{c|}{ Suicides } \\
\cline { 2 - 5 } & Anterior & Posterior & Anterior & Posterior \\
\hline Abrasion & $19(58 \%)$ & $27(79 \%)$ & $10(83 \%)$ & $06(75 \%)$ \\
\hline Contusion & $07(21 \%)$ & $03(9 \%)$ & $01(8 \%)$ & $01(13 \%)$ \\
\hline Laceration & $07(21 \%)$ & $04(12 \%)$ & $01(8 \%)$ & $01(13 \%)$ \\
\hline \multirow{2}{*}{ Total } & $\mathbf{3 3}$ & $\mathbf{3 4}$ & $\mathbf{1 2}$ & $\mathbf{0 8}$ \\
& & & & \\
\hline
\end{tabular}

In the chest both anteriorly and posteriorly abrasion was the commonest injury.

Transection at the level of chest were observed in $9 \%$ of cases which were suicides.

Internal injuries consisted of haemothorax in $6(13 \%)$ accidents and $01 \quad(5 \%)$ suicide and pneumothorax in $01 \quad(2 \%)$ accident.

Table 5 : External abdominal injuries

\begin{tabular}{|c|c|c|c|c|c|}
\hline & \multicolumn{4}{|c|}{ Number of cases } & \multirow{7}{*}{$\begin{array}{l}\text { In the abdominal region } \\
\text { abrasions and lacerations were } \\
\text { the commonest injuries both in } \\
\text { accidents and suicides. } \\
\text { Haemoperitoneum was observed } \\
\text { only in cases of accidents }(6.3 \%) \text {. }\end{array}$} \\
\hline & \multicolumn{2}{|c|}{ Accidents } & \multicolumn{2}{|c|}{ Suicides } & \\
\hline & Anterior & Posterior & Anterior & Posterior & \\
\hline Abrasion & $15(58 \%)$ & $08(89 \%)$ & $05(71 \%)$ & $05(63 \%)$ & \\
\hline Contusion & $04(15 \%)$ & - & $01(14 \%)$ & $01(13 \%)$ & \\
\hline Laceration & $07(27 \%)$ & $01(11 \%)$ & $01(14 \%)$ & $02(25 \%)$ & \\
\hline Total & 26 & 09 & 07 & 18 & \\
\hline
\end{tabular}

Table 6 : Upper limbs and lower limbs

\begin{tabular}{|c|c|c|c|c|c|c|}
\hline & \multicolumn{4}{|c|}{ Number of cases } \\
\hline & & & \multicolumn{2}{|c|}{ Accident } & \multicolumn{2}{|c|}{ Suicide } \\
\hline & & & Anterior & Posterior & Anterior & Posterior \\
\hline \multirow{6}{*}{$\begin{array}{l}\text { Upper } \\
\text { Limb }\end{array}$} & \multirow{4}{*}{$\begin{array}{c}\text { External } \\
\text { injury }\end{array}$} & Abrasion & $25(45 \%)$ & $11(46 \%)$ & $12(55 \%)$ & $03(38 \%)$ \\
\hline & & Contusion & $04(7 \%)$ & $04(17 \%)$ & $01(5 \%)$ & $01(13 \%)$ \\
\hline & & Laceration & $26(46 \%)$ & $09(38 \%)$ & $09(41 \%)$ & $04(50 \%)$ \\
\hline & & Degloving laceration & $01(2 \%)$ & - & - & - \\
\hline & \multicolumn{2}{|l|}{ Total } & 56 & 24 & 22 & 08 \\
\hline & $\begin{array}{l}\text { Other } \\
\text { injuries }\end{array}$ & Traumatic amputation & \multicolumn{2}{|c|}{$02(4 \%)$} & \multicolumn{2}{|c|}{$05(23 \%)$} \\
\hline \multirow{6}{*}{$\begin{array}{l}\text { Lower } \\
\text { Limb }\end{array}$} & \multirow{4}{*}{$\begin{array}{c}\text { External } \\
\text { injury }\end{array}$} & Abrasion & $25(46 \%)$ & $11(50 \%)$ & $12(52 \%)$ & $03(38 \%)$ \\
\hline & & Contusion & $04(7 \%)$ & $04(18 \%)$ & $01(4 \%)$ & $01(13 \%)$ \\
\hline & & Laceration & $26(47 \%)$ & $09(41 \%)$ & $09(39 \%)$ & $04(50 \%)$ \\
\hline & & Degloving laceration & - & & $01(4 \%)$ & \\
\hline & \multicolumn{2}{|l|}{ Total } & 55 & 22 & 23 & 08 \\
\hline & $\begin{array}{l}\text { Other } \\
\text { injuries }\end{array}$ & Traumatic amputation & \multicolumn{2}{|c|}{$03(6 \%)$} & \multicolumn{2}{|c|}{$06(27 \%)$} \\
\hline
\end{tabular}


Abrasions and lacerations were the commonest injuries in both upper and lower extremities. Traumatic amputations were common in suicides than accidents. In suicides traumatic amputation in the upper limbs amounted to $22.7 \%$. Whereas in the lower extremities it was $27.3 \%$. The proportions of lacerations in accidents and suicides involving both upper and lower extremities denote no significant differences.

Table 7 : Brain and spinal cord injury

\begin{tabular}{|l|l|l|}
\hline \multirow{2}{*}{} & \multicolumn{2}{|c|}{ Number of cases } \\
\cline { 2 - 3 } & \multicolumn{1}{|c|}{ Accident } & \multicolumn{1}{c|}{ Suicide } \\
\hline Cerebral laceration & $10(56 \%)$ & $06(67 \%)$ \\
\hline Cerebral contusion & $04(22 \%)$ & $01(11 \%)$ \\
\hline Brain stem injury & $02(11 \%)$ & $02(22 \%)$ \\
\hline Cerebellar injury & $02(11 \%)$ & - \\
\hline Brain injury & $\mathbf{1 8}$ & $\mathbf{0 9}$ \\
\hline Extradural haemorrhage & $04(11 \%)$ & $01(13 \%)$ \\
\hline Subdural haemorrhage & $08(22 \%)$ & $01(13 \%)$ \\
\hline Subarachnoid haemorrhage & $20(54 \%)$ & $06(75 \%)$ \\
\hline Intracerebral haemorrhage & $05(14 \%)$ & - \\
\hline Intracranial haemorrhages & $\mathbf{3 7}$ & $\mathbf{0 8}$ \\
\hline Spinal Contusion & $06(60 \%)$ & - \\
\hline Spinal Laceration & $04(40 \%)$ & $02(100 \%)$ \\
\hline Spinal cord Injury & $\mathbf{1 0}$ & $\mathbf{0 2}$ \\
\hline Transection & $05(10 \%)$ & $05(23 \%)$ \\
\hline
\end{tabular}

In the intracranial injuries subarachnoid hemorrhages shows $54.1 \%$ in accidents and $75 \%$ in suicides. Cerebral lacerations were frequently observed in both accidents (55.6\%) and suicides. (66.7\%). Transactions were observed in $10.4 \%$ of accidents and $22.7 \%$ of suicides.

Table 8 : Visceral injuries

\begin{tabular}{|l|l|l|l|l|}
\hline \multirow{2}{*}{} & \multicolumn{2}{|c|}{ Accident } & \multicolumn{2}{c|}{ Suicide } \\
\cline { 2 - 5 } & Contusion & Laceration & Contusion & Laceration \\
\hline $\begin{array}{l}\text { Heart and } \\
\text { Great vessels }\end{array}$ & $05(21 \%)$ & $11(20 \%)$ & $01(9 \%)$ & $03(14 \%)$ \\
\hline Lungs & $09(38 \%)$ & $10(18 \%)$ & $05(46 \%)$ & $06(26 \%)$ \\
\hline Liver & $03(13 \%)$ & $19(35 \%)$ & $02(18 \%)$ & $07(30 \%)$ \\
\hline $\begin{array}{l}\text { Gastro } \\
\text { intestinal track }\end{array}$ & $02(8 \%)$ & $02(4 \%)$ & $01(9 \%)$ & $02(9 \%)$ \\
\hline Spleen & $03(13 \%)$ & $09(16 \%)$ & $01(9 \%)$ & $03(14 \%)$ \\
\hline Pelvic organs & $02(8 \%)$ & $04(7 \%)$ & $01(9 \%)$ & $02(9 \%)$ \\
\hline Total & $\mathbf{2 4}$ & $\mathbf{5 5}$ & $\mathbf{1 1}$ & $\mathbf{2 3}$ \\
\hline
\end{tabular}

In the visceral injuries the lacerations were predominating in the liver $(34.5 \%)$ in accidents. Whereas contusions were more in the lungs. $(37.5 \%)$. In suicides also contusions were more in the lungs (45.5\%) and lacerations in the liver. 
Table 9 : Skeletal injuries

\begin{tabular}{|l|c|c|}
\hline \multirow{2}{*}{} & \multicolumn{2}{|c|}{ Number of cases } \\
\cline { 2 - 3 } & Accident & Suicide \\
\hline Skull & $34(25 \%)$ & $17(28 \%)$ \\
\hline Cervical Spine & $17(13)$ & $08(13 \%)$ \\
\hline Thoracic Spine & $07(5 \%)$ & $04(7 \%)$ \\
\hline Lumbar Spine & $01(1 \%)$ & $01(2 \%)$ \\
\hline Pelvis & $07(5 \%)$ & $03(5 \%)$ \\
\hline Ribs & $35(26 \%)$ & $09(15 \%)$ \\
\hline Upper Limb & $14(10 \%)$ & $08(13 \%)$ \\
\hline Lower Limb & $21(15 \%)$ & $10(2 \%)$ \\
\hline Total & 136 & 60 \\
\hline
\end{tabular}

Skull fracture is the commonest fracture involving $25 \%$ of accidents and $28.3 \%$ of suicides. This illustrates the vulnerability of the head region in succumbing to injuries.

The analysis of cause of death revealed that multiple injuries (49.1\%) was the commonest in accidents followed by head injuries. (27.3\%) The same phenomenon was observed in suicides also where it amounted to $73.3 \%$ and $49.1 \%$ respectively (Table 10 ).

Table 10: Cause and manner of death

\begin{tabular}{|l|l|l|}
\hline \multirow{2}{*}{\multicolumn{1}{c|}{ Cause of death }} & \multicolumn{2}{c|}{ Number of cases } \\
\cline { 2 - 3 } & \multicolumn{1}{c|}{ Accident } & \multicolumn{1}{c|}{ Suicide } \\
\hline Related to head injury & $15(27 \%)$ & $05(33 \%)$ \\
\hline Multiple injuries & $27(49 \%)$ & $11(73 \%)$ \\
\hline Multiple injuries in two regions & $04(7 \%)$ & $02(13 \%)$ \\
\hline Chest injury & $01(2 \%)$ & - \\
\hline Abdominal injury & $01(2 \%)$ & - \\
\hline Decapitation & - & $03(20 \%)$ \\
\hline Transection & - & $01(7 \%)$ \\
\hline Total & 48 & 22 \\
\hline
\end{tabular}

\section{DISCUSSION}

Research of this nature is vital in Sri Lanka considering the fact that not many rail roads related studies had been done in the recent past. The analysis of deaths from railway related incidents gives an overall understanding of the main circumstances and other contributory factors. The interpretation of regional injuries helps to solidify the different circumstances.
The literature review reveals several studies from the neighboring country in relation to railway track deaths. ${ }^{5,6,7}$

In most instances the most reliable history comes from the train driver himself. Unfortunately, due to practical difficulties the history is often obtained from by standers and other eyewitnesses related to the incident. Therefore, the reliability of the 
correct history is an issue in relation to railroad accidents and suicides.

Identifying the circumstance by corroborating the injury pattern with the given history is one of the main issues that needs to be addressed with great caution. In selected situations when the injuries are mutilating the body the identification also becomes a problem. Meticulous external and internal examination, documentation and interpretation of injuries would circumvent most of the medico-legal issues. Though scene visit is an important component of autopsy examination none of the cases in this study necessitated such a retrospective visit.

Majority of the victims were male and in the age group of 20-39 years. Male predominance has been shown in several studies. $^{5,6,7}$ The young adults are more prone to collision with trains and could be due to several reasons. In cases of accidents mobile phone usage, carelessness of the motor vehicle drivers, travelling through the railway crossing when the gates are closed, try to climb or get down from a moving train are some of the identified factors. The deaths can be reduced due to awareness campaigns among public, strict enforcement of law and enhancement of protective mechanisms. The scarcity of studies related to railroad deaths in Sri Lanka and lack of enthusiasm to carry out major studies, less funding in forensic related research are some of the hindrances. In cases of suicides the exact reasons for selecting the railway track, anticipating a collision with a moving train could not be identified with the available samples.

Most of the incidents took place at the railway crossing and along the railway track away from the railway stations. Though the majority of accidents took place during the early night hours (6-10 pm) and late evenings $(2-6 \mathrm{pm})$ there are no reasons to correlate this observation. One of the factor could be the afterward rush hours and the hurriedness to break through the signals and closed doors before an approaching train. The carelessness of the pedestrian would always be the leading factor unless proven otherwise. Interestingly a recent study revealed that the speed of the train is an important deciding factor in the severity of injuries rather than the day, time and place. Although poor illumination may be a contributory factor but it is not a major determinant according to this study. ${ }^{8}$ In contrast a German study revealed marked seasonal, weekly and diurnal peaks of railway suicide intensity. Differences between men and women indicate sexspecific processes underlying their suicidal behaviour. ${ }^{9}$

A study involving the New York city found suicides were more common than accidents. The important message is in railroad fatalities is that the injury interpretation involves mostly accidents and suicides. The deaths related to other circumstances are few. ${ }^{10}$

There were several injuries in both external and internal examination. In the head and neck region the external injuries such as abrasion, and laceration were relatively more in comparison to contusions. But the decapitation injuries were significantly observed in suicides only. Therefore, decapitation injuries may be commonly associated with suicides provided no other suspicious injuries caused by infliction. ${ }^{4}$ In Sri Lanka it is a known factor that individuals keep their head in the railway track to be run over by the moving train.

The analysis of chest injuries also follows a pattern where the abrasions were the commonest injury in comparison to lacerations and contusions. However, transection at the chest level is typical for suicides when a person decides to end his life by lying across a railway track to be transected by a speeding train., 5 This injury pattern will promote the interpretation of the circumstances in the absence of a definite or reliable history. In this study transection were only observed in suicides. 
In the external injuries abrasions were comparatively more in the abdomen in both accidents and suicides. The proportion of traumatic amputation of extremities was significantly higher in suicides. This again explains the relative position of a victim in committing suicide by lying across the track and thus the involvement of extremities.

In this study the analysis of visceral injuries especially with relation to brain revealed the brain lacerations $(66.7 \%)$ and other types of haemorrhages more specifically the subarachnoid haemorrhage $(75 \%)$ is more common with suicides than accidents. It implies that the relative involvement of head is more common with suicides than accidents. In contrast there is no difference in the percentage of skull fractures showing $25 \%$ in accidents and $28.3 \%$ in suicides. Unlike external injuries there is no specific type of internal injuries that could be identified with suicides. In summary considering the external injuries transections and traumatic amputations are more common in suicides. Though there were several studies related to railway deaths similar observations in selected situations were present in the neighboring country. ${ }^{4,5,7,10}$

In most of the deaths taking place at rail roads more than the cause of death, identifying the correct circumstances is the main challenging medico-legal issue. Careful interpretation of the external and internal injuries will prevent human errors in deciding the exact circumstance. Finally, a ten year study from Turkey revealed a mortality rate of $16 \%$ and morbidity rate of $37 \%$ further highlighting the relevance of rail road injuries in clinical patients. ${ }^{11}$

The most common cause of death in both accidents and suicides were due to multiple injuries. It is acceptable considering the speed, impact and heavy metal involvement in collision with human subjects. Further head injuries alone were accounted in several deaths.
The most common circumstance was accident $(68.6 \%)$ and in most instances it was preventable. The next common was suicide. Though the death would be traumatic and painful or may end up with lifelong disabilities several choose collision with a moving train as a mode of death to end their lives. The suicides took place in areas away from the crossings and railway stations. The victims made sure of a death from fatal injuries. This further emphasizes the role of railway authorities to be vigilant to minimize these deaths even though trespassing into or along the railway track is not permitted in Sri Lanka. A systematic review reported in the BMC public health revealed 'empirical evidence for socio environmental factors for railway suicide is limited and inconsistent." The same observations made in this study as well with limited data available to determine the exact reasons to choose this mode of death and thus limiting the preventive measures. ${ }^{12,13}$

\section{CONCLUSION}

Majority of rail road deaths were accidental. Transections of neck, chest and traumatic amputations of extremities were commoner in suicides than in accidents.

\section{RECOMMENDATION}

Rail road deaths could be reduced with increased public awareness, enhanced protective mechanism at rail crossings and strict enforcement of the law. In relation to suicides in depth analysis must be done to identify the factors which prompt the victims to choose rail roads to end their lives.

\section{ACKNOWLEDGEMENT}

Dr. Deepal Fernando for providing some of his cases.

Mr. Ramesh Wijesinghe for the assistance with data analysis and graphs. 


\section{REFERENCE}

1. Sri Lanka Railways [Internet]. Sri Lanka: Sri Lanka Railways; 2011 [updated 2011; Available from: http://www.railway.gov.lk/

2. Performance Report- 2016 [Internet]. Sri Lanka: Parliament of Sri Lanka, Department of Sri Lanka Railway; 2016 [updated 2018 May 10; Available from: http://www.parliament.lk/uploads/documen ts/paperspresented/performance-reportdepartment-of-srilanka-railway-2016.pdf

3. Ministry of Transport and Civil Aviation [Internet]. Sri Lanka; Ministry of Transport and Civil Aviation; 2018 [updated $2018 \mathrm{Jul}$ 12; Available from: http://www.transport.gov.lk

4. Byard RW, Gilbert JD. Characteristic features of deaths due to decapitation. The American Journal of Forensic Medicine and Pathology. 2004; 25(2): 129-30.

DOI: $\quad$ https://doi.org/10.1097/01.paf. 0000127400.12824.f9

5. Sheikh MI, Shah JV, Patel R. Study of death due to railway accident. Journal of Indian Academy of Forensic Medicine. 2008; 30(3): 122-7.

6. Valsala K, Sreedevi CS, Sreelekshmi J. Analysis of railway track deaths-an autopsy based study. International Journal of Research in Medical Sciences. 2017; 5(3): 935-9.

DOI: http://dx.doi.org/10.18203/23206012.ijrms20170639

7. Kumar PR. A study of deaths due to railway fatalities at a tertiary care hospital mortury 2015-16. International Journal of Research in Medical Sciences. 2017; 6(1): 264-7. DOI: http://dx.doi.org/10.18203/23206012.ijrms20175731
8. Ghomi H, Bagheri $\mathrm{M}, \mathrm{Fu}$ L, MirandaMoreno LF. Analyzing injury severity factors at highway railway grade crossing accidents involving vulnerable road users: A comparative study. Traffic Injury Prevention. 2016; 17(8): 833-41.

DOI: https://doi.org/10.1080/15389588. 2016.1151011

9. Erazo N, Baumert J, Ladwig KH. Sexspecific time patterns of suicidal acts on the German railway system. An analysis of 4003 cases. Journal of Affective Disorders. 2004; $83(1)$ : $1-9$. DOI: https://doi.org/10.1016/j.jad.2004. 04.012

10. Lin PT, Gill JR. Subway Train-Related Fatalities in New York City: Accident versus Suicide. Journal of Forensic Sciences. 2009; 54(6): 1414-8.

DOI: $\quad$ https://doi.org/10.1111/j.15564029.2009.01165.x

11. Akkaş M, Ay D, Metin Aksu N, Günalp M. 10 -year evaluation of train accidents. Ulus Travma Acil Cerrahi Derg. 2011; 17(5): 440-4.

DOI: https://doi.org/10.5505/tjtes.2011. 66750

12. San Too L, Milner A, Bugeja L, McClure R. The socio-environmental determinants of railway suicide: a systematic review. BMC Public Health. 2014; 14(1): 20.

DOI: https://doi.org/10.1186/1471-245814-20

13. Taylor AK, Knipe DW, Thomas KH. Railway suicide in England and Wales 2000-2013: a time-trends analysis. BMC Public Health. 2016; 16(1): 270.

DOI: https://doi.org/10.1186/s12889-0162944-x 